REVISTA 89.1

Revista RELACIONES INTERNACIONALES

Escuela de Relaciones Internacionales.

Universidad Nacional, Costa Rica.

N. ${ }^{\circ} 89.1$ • Enero-Junio de 2016

doi: http://dx.doi.org/10.15359/ri.89-1.9

Pp. 191-210

\title{
LA PARTICIPACIÓN DE COSTA RICA EN EL MARCO DEL SISTEMA MULTILATERAL DE COMERCIO
}

\author{
Jeannette Valverde Chaves* \\ Deyda María Monge Ureña**
}

\section{RESUMEN:}

Costa Rica ha sido un baluarte en comercio exterior, siempre presente en la Ronda de Uruguay, en el Acuerdo General sobre Aranceles y Comercio (GATT) y firmante de la Organización Mundial del Comercio (OMC). =

El artículo describe el proceso de adhesión de Costa Rica al sistema multilateral de comercio, desde la negociación y adhesión al Acuerdo General Aranceles y Comercio (GATT) hasta su ingreso como miembro fundador a la Organización Mundial del Comercio (OMC) y la participación que ha tenido el país en este importante foro de comercio mundial.

Palabras clave: sistema multilateral de comercio, GATT, OMC, Costa Rica, comercio internacional.

\begin{abstract}
:
Costa Rica has been a bulwark in foreign trade, always present in the Uruguay Round of the General Agreement on Tariffs and Trade (GATT) and a signatory to the World Trade Organization (WTO).

The article describes the process of accession of Costa Rica to the multilateral trading system, from negotiation and accession to the General Agreement Tariffs and Trade (GATT) to its income and founder of the World Trade Organization (WTO) membership and participation has had the country at this important forum of world trade.
\end{abstract}

Keywords: Multilateral trading system, GATT, WTO, Costa Rica, international trade.

* Doctora en Estudios Latinoamericanos con énfasis en Pensamiento Latinoamericano, Máster en Relaciones Internacionales con énfasis en Negocios Internacionales ambos por la Universidad Nacional de Costa Rica y especialidad en Responsabilidad social empresarial por la Universidad de Buenos Aires, Argentina. Es catedrática de la Universidad Nacional de Costa Rica. Labora como docente e investigadora en la Escuela de Relaciones Internacionales en la Universidad Nacional de Costa Rica. Correo electrónico: Jeannette.valverde.chaves@una.cr

** Máster en Relaciones Internacionales y Diplomacia con Énfasis en Proyectos de Cooperación Internacional. Labora como consejera y encargada de Asuntos Consulares de la Embajada de Costa Rica en México. Correo electrónico: deydamonge@hotmail.com 


\section{Introducción}

Costa Rica ha sido un país con una vocación proactiva en materia de comercio internacional, prueba de ello es su participación permanente y continua en la Ronda de Uruguay, el Acuerdo General sobre Aranceles y Comercio (GATT) y la Organización Mundial del Comercio (OMC), desde sus inicios; situación que se ha visto fortalecida con la transformación de su modelo agro exportados tradicional a un modelo enfocado a la exportación de productos no tradicionales y la atracción de inversiones; todo esto impulsado y favorecido por las acciones particulares de los gobiernos de la última década del siglo pasado y en proceso de fortalecimiento en la primer década del siglo XXI, con miras hacia una futura consolidación.

Para ello es necesario que el país desarrolle capacidades de conocimiento y estrategias que le faciliten sus negociaciones comerciales, la atracción de negocios e inversiones y los procesos de producción nacional, orientados a aprovechar las ventajas comerciales derivadas de los convenios y tratados comerciales que ha firmado y que firmará en el futuro. Una de las maneras de crear, desarrollar y fortalecer esas capacidades es mediante la cooperación técnica que se puede recibir de entes especializados o de naciones más avanzadas en esa materia. Es así como se ha visto la importancia y conveniencia de analizar el nivel de aprovechamiento del país en la cooperación técnica que la OMC pone a disposición de sus socios, para la construcción de capacidades tendientes al desarrollo de mejores niveles de competitividad en materia comercial.

Costa Rica, en su largo caminar, buscando el desarrollo económico y el bienestar de su pueblo, históricamente ha incursionado en diferentes modelos de desarrollo y desde las dos últimas décadas del siglo anterior, puso en práctica la promoción de las exportaciones.

\section{Adhesión de Costa Rica al GATT}

Mediante decisión del Consejo de Gobierno, el 3 de julio de 1985, Costa Rica solicitó formalmente la adhesión del país al GATT, dicha solicitud tuvo como objetivo cumplir con el compromiso del país suscrito en la Iniciativa de la Cuenca del Caribe, obtener la prueba de daño que se constituía en un mecanismo de defensa para las exportaciones no tradicionales, participar en el principal foro comercial internacional, beneficiarse de las instancias del GATT para la solución de controversias comerciales, obtener información y asistencia técnica y aprovechar la existencia de intereses comunes con países en desarrollo y el 24 de noviembre de 1990, Costa Rica se convirtió formalmente en el centenario Estado en ser parte contratante del GATT (OMC, 2015). 
Sin duda alguna, la participación de Costa Rica en el sistema multilateral de comercio no obedeció a una decisión arbitraria, sino por el contrario, es parte de una política comercial coherente que busca la exitosa inserción del país en la economía mundial.

En la siguiente figura se muestra una cronología de la participación de Costa Rica en el sistema multilateral del comercio.

- Rondas de negociación

- Lanzamiento de la Ronda de Uruguay e inicio de la adhesión de Costa Rica al GATT

1990 • El 24 de noviembre de 1990, Adhesión de Costa Rica al GATT

1995 - Establecimiento de la OMC

2011 • Lanzamiento de la Ronda de Doha

2003 • Reunión Ministerial de Cancún

2005 • Reunión Ministerial de Hong Kong

2008 • Paquete de julio, fracaso en la conclusión de modalidades

2009 . Reanudación de las negociaciones

2010

2011

- Reanudación de negociación con miras a concluir en diciembre de 2011

Figura 1. Cronología de la participación de Costa Rica en el SMC.

Elaboración propia a partir de Ronald Saborío (2014).

\section{Participación de Costa Rica en la OMC}

\section{Desde su adhesión}

La Organización Mundial del Comercio es una institución regida por sus 157 miembros. Los últimos en adherirse fueron Rusia, el 22 de agosto de 2012, y Vanuatu 24 de agosto de ese mismo año. La OMC es foro permanente donde se negocian nuevos acuerdos, se solventan conflictos comerciales y está presente para dar seguridad a los intercambios que se realicen (OMC, 2015). 
También vela por las normas establecidas, procura una mayor liberalización económica, cada cierto tiempo revisa el régimen comercial de sus miembros y brinda asistencia técnica a los países en desarrollo en procura de su bienestar y de la óptima inserción en el mundo económico.

La participación del país en la OMC está regulada mediante la Ley 7638 de 1996 que creó el Ministerio de Comercio Exterior y la Promotora de Comercio de Exterior.

El Ministerio de Comercio Exterior tiene como atribuciones, definir y dirigir la política comercial externa y de inversión extranjera, dirigir las negociaciones comerciales y de inversión bilaterales y multilaterales, suscribir tratados y convenios, y representar al país en la OMC y demás foros comerciales internacionales donde se discutan temas de comercio e inversión.

Con respecto a la $\mathrm{OMC}$, el artículo 2, inciso e establece lo siguiente:

Representar al país en la Organización Mundial del Comercio y en los demás foros comerciales internacionales donde se discutan tratados, convenios y, en general, temas de comercio e inversión. (p.1)

Y en el artículo 5 la Delegación Permanente ante la Organización Mundial del Comercio:

La Delegación Permanente de Costa Rica ante la Organización Mundial del Comercio formará parte del Ministerio de Comercio Exterior y dependerá de él para todos los efectos. Con el fin de dotarla de las plazas y los servicios necesarios, se creará un programa específico dentro del presupuesto de este Ministerio. A los miembros de la Delegación se les aplicarán, en lo conducente, las disposiciones del Estatuto del Servicio Exterior de la República, Ley No. 3530, de 5 de agosto de 1965, de conformidad con el reglamento que el Poder Ejecutivo dictará por medio de dicho Ministerio. (p. 3)

Al ser un país pequeño y en vías de desarrollo, la participación de Costa Rica en este importante foro comercial resulta de vital importancia, porque le permite al país gozar de beneficios y acuerdos para la promoción y la apertura comercial, así como disfrutar de la disminución arancelaria que se ha venido gestando desde los tiempos del GATT.

De acuerdo con la señora Anabel González (2001), autora de la ponencia Costa Rica y la Organización Mundial del Comercio: Impacto hasta el presente y expectativas hacia el futuro, presentada en el marco de la visita del director de la 
OMC, Mike Moore a Costa Rica en el año 2001, "la OMC ha tenido un impacto muy importante en el campo institucional en Costa Rica, ha promovido el mejoramiento, modernización y transparencia del régimen de comercio exterior en muchas áreas" (p. 12).

Tal y como se indica en el Examen de Políticas Comerciales de Costa Rica ante la OMC (2013):

Costa Rica es miembro fundador de la OMC y otorga al menos el trato de nación más favorecida (NMF) a todos sus interlocutores comerciales. Costa Rica participa en el Acuerdo de Tecnología de la Información de la OMC y participó en las negociaciones sobre los servicios financieros, aceptando el Quinto Protocolo anexo al Acuerdo General sobre el Comercio de Servicios (AGCS). Costa Rica no participó en las negociaciones sobre telecomunicaciones y no es parte ni observador en ningún acuerdo plurilateral. Es un miembro activo de la OMC, tanto en la labor ordinaria, como en la Ronda de Desarrollo de Doha. (p. 9)

Desde mediados de la década de 1990, Costa Rica ha construido una plataforma para el comercio exterior que se fundamenta en las reglas y disciplinas establecidas en la $\mathrm{OMC}$, los instrumentos de la integración económica centroamericana y los tratados de libre comercio (TLC). En el caso de los últimos, Costa Rica tiene en vigor 12 TLC que rigen el comercio con 44 socios comerciales, los cuales cubren el $84,4 \%$ del comercio total, un $86,4 \%$ de las exportaciones y un $83,2 \%$ de las importaciones totales del país (COMEX, 2014).

Desde su adhesión al GATT, Costa Rica país participa activamente en los diferentes grupos de trabajo y foros que desarrolla El sistema multilateral de comercio. La OMC constituye el fundamento de la política comercial y el principal foro de discusión con los socios comerciales.

Según declaraciones formuladas por la entonces Presidenta de la República, Sra. Laura Chinchilla Miranda, durante la reunión de la OMC el 19 de setiembre del 2011, (OMC, 2011, p. 2):

...el libre comercio que Costa Rica favorece no habría sido posible nunca sin la existencia de la OMC. Esta Organización garantiza el entorno jurídico institucional que hace posible la realización de nuestras aspiraciones. En la OMC, mi país se ha encontrado con las naciones más ricas, algunas veces en disputas que han conducido al restablecimiento de nuestros derechos y otras en negociaciones con intereses difíciles de conciliar. Sin embargo, lo más habitual para nosotros ha sido participar en alianzas que buscan beneficios comunes dentro de una mayor liberalización. 
La OMC también le ha ofrecido a una nación pequeña, como Costa Rica, hablar con la misma fuerza que naciones más grandes. Y lo hemos hecho sin complejos. Siguiendo nuestra vocación de actuar conforme a derecho, hemos encontrado espacio para defendernos, para utilizar nuestras ventajas comparativas y para reivindicar los derechos que nos otorgan los acuerdos de la OMC. Este entorno jurídico reafirma la confianza de los pueblos en el Derecho Internacional Público y por ello no debemos claudicar frente a las tareas pendientes que nos permitan fortalecer aún más la institucionalidad multilateral en materia de comercio e inversión.

La participación de Costa Rica no se ha limitado al cumplimiento de las normas y disciplinas, sino que como socio fundador, el país participa activamente aportando, de manera importante, en temas como La facilitación del comercio y los servicios. Además, de manera puntual, el país ha propuesto una reforma agrícola con el objetivo de que los productos agrícolas alcancen un trato similar al que han recibido los productos no agrícolas; también ha buscado dar cumplimiento al mandato para los productos tropicales y alternativos.

Costa Rica fue la primera nación latinoamericana en adherirse al Acuerdo sobre Tecnología de la Información; además, participó en las negociaciones sobre los servicios financieros y adoptó el Quinto Protocolo; estuvo como observador en el Grupo de Negociación sobre Telecomunicaciones Básicas.

(OMC, 2001, p. 8)

Por otra parte, en cuanto a las negociaciones no agrícolas, Costa Rica apoya un mayor acceso a los mercados con reglas más claras y apoya el compromiso de aclarar y mejorar las normas de la OMC, en particular en materia de antidumping, y reforzar el papel del entendimiento de solución de diferencias. Sobre este mismo tema, Costa Rica participa en las negociaciones para ampliar la cobertura del Acuerdo Sobre Tecnología de la Información (ATI).

En materia de solución de controversias, desde su adhesión, Costa Rica ha participado como demandante en cinco casos y como tercero en quince. Uno de los más representativos ha sido el Acuerdo de Ginebra sobre el Comercio de Bananos, una de las diferencias más largas de la historia del GATT y la OMC. $\mathrm{El}$ acuerdo fue firmado por Costa Rica, la UE y otros países latinoamericanos en mayo de 2010 y entró en vigor en marzo de 2011.

En materia de mecanismo de solución de diferencias, Costa Rica ha participado en varias ocasiones como parte demandante y como tercera parte, nunca ha sido demandado. Como demandante contra Estados Unidos sobre restricciones a textiles (1996), contra la Unión Europea por restricciones al banano (1992, 
1993, 1997, 2005) y contra la República Dominicana por la salvaguardia a los sacos de polipropileno (2011), como tercera parte en 15 casos.

Con respecto a los tratados de libre comercio (TLC) en vigor, Costa Rica mantiene vigentes acuerdos regionales con Centroamérica desde 1963, República Dominicana desde 2002, con Chile desde 2002; la renegociación del acuerdo con Panamá entró en vigencia en el año 2008, el CAFTA desde el 2009, el acuerdo entre Centroamérica y México desde 2013, reformado - este acuerdo sustituye el acuerdo bilateral entre Costa Rica y México-, y está pendiente la entrada en vigencia del Acuerdo de Asociación con la Unión Europea. Todos estos acuerdos son multilaterales y su participación contempla a los países centroamericanos.

En el ámbito bilateral, Costa Rica tiene suscrito un acuerdo con México desde 1995, con Canadá desde el 2002, con la Comunidad del Caribe desde el 2005, con China desde el 2011, con Singapur, Colombia y Perú desde el 2013.

Como se indicó en páginas anteriores, Costa Rica durante el período de 2007 a 2013 ha adoptado 125 reglamentos técnicos; la mayoría de ellos se relacionaron con productos como plaguicidas, combustibles, medicamentos, textiles, cosméticos y alimentos (COMEX, 2015).

Adicionalmente, en materia de zonas francas, Costa Rica notificó a la OMC que algunos aspectos del Régimen de Zonas Francas (RZF) y el Régimen de Perfeccionamiento Activo constituían subvenciones a las exportaciones y, en 2007, obtuvo una prórroga del plazo para eliminar esas subvenciones hasta el 31 de diciembre de 2015 (OMC, 2013). Para cumplir con este compromiso y brindar seguridad jurídica a la inversión, Costa Rica reformó la Ley del Régimen Zona Franca en 2010. Las principales reformas fueron la eliminación de los requisitos de exportación para las empresas beneficiarias del Régimen de Zona Francas y de las restricciones sobre las ventas al mercado local. Otros cambios fueron la introducción de incentivos fiscales diferenciados para atraer a empresas a zonas de menor desarrollo, así como a inversiones de gran volumen; la creación de créditos fiscales por la capacitación de personal, y disposiciones para fortalecer los encadenamientos productivos y el desarrollo de proveedores locales (OMC, 2013).

Desde 2007 Costa Rica ha realizado reformas para modernizar su sistema de propiedad intelectual con el fin de adaptarlo a los avances tecnológicos y cumplir con sus compromisos internacionales. Las reformas legislativas han abarcado prácticamente todos los derechos de propiedad intelectual y el régimen de observancia. 
En 2008 se promulgó la Ley de Protección de las Obtenciones Vegetales y en 2009 su reglamento. En 2011, Costa Rica aceptó el Protocolo por el que se enmienda el Acuerdo sobre los Acuerdo de Derechos de Propiedad Intelectual relacionados con el comercio, (ADPIC) relativo al párrafo 6 de la Declaración de Doha sobre el ADPIC y la Salud Pública.

Finalmente, Costa Rica ha desarrollado una estrategia con miras a formar parte de la Alianza del Pacífico y en la Organización para la Cooperación y el Desarrollo Económico (OCDE). (OMC, 2013, p. 9)

\section{Participación de Costa Rica en los foros de la OMC}

Desde su adhesión a la Organización Mundial del Comercio, Costa Rica ha tenido una activa participación y liderazgo en los órganos regulares y de negociación (ver tabla 1).

\section{Tabla 1.}

Participación de Costa Rica en grupos

\begin{tabular}{|c|l|l|}
\hline Año & Función/Puesto & \multicolumn{1}{|c|}{ Grupo } \\
\hline 1998 & Presidencia & $\begin{array}{l}\text { Consejo de Comercio de Mercancías y del Comité } \\
\text { del Acuerdo de Tecnologías de Información (ITA) }\end{array}$ \\
\hline & Presidencia & $\begin{array}{l}\text { Negociaciones sobre comercio y derechos laborales, } \\
\text { en Seattle }\end{array}$ \\
\hline 2001 & Vicepresidencia & Conferencia Ministerial de Doha \\
\hline $2001-2003$ & Presidencia & Grupo de Transparencia en la contratación pública \\
\hline 2004 & Presidencia & Comité antidumping \\
\hline $2004-2005$ & Presidencia & Comité de Acuerdos Comerciales Regionales \\
\hline $2006-$ presente & Presidencia & $\begin{array}{l}\text { Grupo de negociación para la revisión del } \\
\text { entendimiento solución de diferencias }\end{array}$ \\
\hline
\end{tabular}

Nota: Elaboración propia a partir del material del Seminario Introductorio al Sistema Multilateral de Comercio, 2014.

Adicionalmente el país ha participado activamente en los siguientes talleres de capacitación (tabla 2): 
Tabla 2.

Participación de Costa Rica en talleres de capacitación

\begin{tabular}{|c|c|c|}
\hline $\begin{array}{c}\text { Nombre de la } \\
\text { actividad }\end{array}$ & Lugar y fecha & Objetivo \\
\hline $\begin{array}{l}\text { El Acuerdo sobre } \\
\text { Contratación } \\
\text { Pública de la OMC: } \\
\text { Importancia para } \\
\text { el desarrollo y el } \\
\text { comercio, evolu- } \\
\text { ción del contexto } \\
\text { y perspectivas } \\
\text { futuras }\end{array}$ & $\begin{array}{l}\text { Ginebra, Suiza, } 11 \\
\text { y } 12 \text { de febrero de } \\
2010\end{array}$ & $\begin{array}{l}\text { El Acuerdo sobre Contratación Pública de } \\
\text { la OMC: Importancia para el desarrollo y el } \\
\text { comercio, evolución del contexto y perspec- } \\
\text { tivas futuras }\end{array}$ \\
\hline $\begin{array}{l}\text { Taller regional de la } \\
\text { OMC sobre contra- } \\
\text { tación pública para } \\
\text { países de América } \\
\text { Latina }\end{array}$ & $\begin{array}{l}\text { Montevideo, } \\
\text { Uruguay } \\
20 \text { a } 22 \text { de mayo } \\
\text { de } 2008\end{array}$ & $\begin{array}{l}\text { i) reforzar en los participantes el conoci- } \\
\text { miento de los conceptos y principios clave } \\
\text { en la esfera de la contratación pública; ii) } \\
\text { familiarizarlos con las actividades perti- } \\
\text { nentes de la OMC -en particular el texto } \\
\text { revisado y acordado provisionalmente, del } \\
\text { Acuerdo sobre Contratación Pública (ACP)- } \\
\text { y examinar las ventajas y los obstáculos que } \\
\text { puede suponer la adhesión al Acuerdo; y iii) } \\
\text { facilitar el desarrollo de políticas y la toma } \\
\text { de decisiones en esta esfera a nivel nacional } \\
\text { y regional }\end{array}$ \\
\hline
\end{tabular}




\begin{tabular}{|c|c|c|}
\hline $\begin{array}{c}\text { Nombre de la } \\
\text { actividad }\end{array}$ & Lugar y fecha & Objetivo \\
\hline $\begin{array}{l}\text { Taller regional de la } \\
\text { OMC sobre contra- } \\
\text { tación pública para } \\
\text { países de América } \\
\text { Latina }\end{array}$ & $\begin{array}{l}\text { Buenos Aires, } \\
\text { Argentina del } 5 \text { al } \\
7 \text { de abril de } 2006\end{array}$ & $\begin{array}{l}\text { El objetivo del taller es brindar un foro en el } \\
\text { que expertos en comercio y en contratación } \\
\text { puedan intercambiar información sobre acti- } \\
\text { vidades e iniciativas nacionales, bilaterales, } \\
\text { regionales y multilaterales relacionadas } \\
\text { con el comercio en la esfera de la contra- } \\
\text { tación pública. Los objetivos generales del } \\
\text { programa son: i) reforzar en los participantes } \\
\text { el conocimiento de los conceptos y princi- } \\
\text { pios clave en esta esfera; ii) familiarizarlos } \\
\text { con las actividades pertinentes de la OMC; } \\
\text { y iii) facilitar el desarrollo de políticas y la } \\
\text { toma de decisiones en esta esfera a nivel na- } \\
\text { cional y regional. El programa adopta un en- } \\
\text { foque interactivo en el que se hace hincapié } \\
\text { en las sesiones específicas en él incluidas, } \\
\text { para alentar la consideración de cuestiones } \\
\text { prácticas, la creación de redes de coopera- } \\
\text { ción, así como el intercambio de información } \\
\text { y la puesta en común de experiencias }\end{array}$ \\
\hline $\begin{array}{l}\text { Taller regional } \\
\text { conjunto OMC/ } \\
\text { BID/INTAL sobre } \\
\text { contratación públi- } \\
\text { ca para países de } \\
\text { América Latina }\end{array}$ & $\begin{array}{l}\text { Santo Domingo, } \\
\text { República Domi- } \\
\text { nicana, } 26 \text { al } 28 \text { de } \\
\text { octubre de } 2004\end{array}$ & $\begin{array}{l}\text { Brindar un foro en el que los expertos del } \\
\text { área de comercio y de contratación pública } \\
\text { puedan intercambiar información sobre las } \\
\text { actividades relativas al comercio a nivel } \\
\text { nacional, bilateral, regional y multilateral y } \\
\text { sobre iniciativas en materia de contratación } \\
\text { pública }\end{array}$ \\
\hline
\end{tabular}

Nota: Elaboración propia a partir del material recuperado de la página web www.omc/costarica (2014).

De acuerdo con el Embajador Ronald Saborío (2014) Costa Rica participa en el trabajo técnico de los distintos órganos de la OMC. Esto incluye la vigilancia del cumplimiento de los otros miembros y la presentación de posiciones en defensa de intereses nacionales específicos, vigilancia del cumplimiento propio y la presentación de las notificaciones requeridas por los Acuerdos de la OMC, y de manera general a través de la presentación de posiciones sobre los distintos temas tratados por cada uno de los órganos. 
Por otra parte, con respecto a los exámenes de políticas comerciales, Costa Rica ha sido sujeto a cuatro $(1995,2001,2007,2013)$ y a la vez participa activamente en los exámenes de las políticas comerciales de sus principales socios comerciales (por ejemplo, a través de presentaciones orales, planteamiento de preguntas escritas). Así, en 2014 participó en los exámenes de políticas comerciales de Taipéi Chino, Hong Kong, Ucrania y los Estados Unidos (Saborío, 2014).

Costa Rica ha participado activamente en las negociaciones de Doha a través de alianzas con otros grupos de países (tabla 3):

Tabla 3.

Participación de Costa Rica en alianzas

\begin{tabular}{|l|l|l|}
\hline \multicolumn{1}{|c|}{ Alianza } & \multicolumn{1}{|c|}{ Integrantes } & \multicolumn{1}{c|}{ Objetivo } \\
\hline \multirow{5}{*}{$\begin{array}{l}\text { Friends of the } \\
\text { System }\end{array}$} & $\begin{array}{l}\text { Australia, Canadá, Chile, } \\
\text { Colombia, Costa Rica, México, } \\
\text { Hong Kong, Japón, Corea, Nueva } \\
\text { Zelanda, Noruega, Paraguay, } \\
\text { Singapur, Suiza, Unión Europea, } \\
\text { Brunei, China Taipéi, Islandia, } \\
\text { Israel, Jamaica, Malasia, Tailan- } \\
\text { dia, Turquía, Uruguay, Vietnam, } \\
\text { Mauricio, Bangladesh, Egipto, } \\
\text { Nigeria. }\end{array}$ & $\begin{array}{l}\text { Interesados en que haya } \\
\text { progresos en la agenda de } \\
\text { trabajo de la OMC y que } \\
\text { esta cumpla su mandato }\end{array}$ \\
\hline \multirow{5}{*}{$\begin{array}{l}\text { Old School } \\
\text { Friends }\end{array}$} & $\begin{array}{l}\text { Hong Kong (Coordinador), Aus- } \\
\text { tralia, Chile, Colombia, Costa } \\
\text { Rica, México, Noruega, Nueva } \\
\text { Zelandia y Singapur. }\end{array}$ & $\begin{array}{l}\text { Países con posiciones de } \\
\text { mayor ambición en los } \\
\text { diferentes temas de la } \\
\text { agenda de trabajo de la }\end{array}$ \\
\hline OMC. \\
Grupo Cairns
\end{tabular}




\begin{tabular}{|c|c|c|}
\hline Alianza & Integrantes & Objetivo \\
\hline $\begin{array}{l}\text { Grupo de Produc- } \\
\text { tos Tropicales }\end{array}$ & $\begin{array}{l}\text { Bolivia, Colombia, Costa Rica } \\
\text { (coordinador), Ecuador, Guate- } \\
\text { mala, Nicaragua, Panamá y Perú. }\end{array}$ & $\begin{array}{l}\text { Coalición de países que } \\
\text { promueven la máxima li- } \\
\text { beralización del comercio } \\
\text { de productos tropicales en } \\
\text { los mercados de los países } \\
\text { desarrollados. Logró en el } \\
2004 \text { que se convirtiera en } \\
\text { un mandato de la Ronda } \\
\text { Doha y llevó a los acuer- } \\
\text { dos de banano y productos } \\
\text { tropicales del } 2009 \text {. }\end{array}$ \\
\hline Grupo Colorado & $\begin{array}{l}\text { Australia, Canadá, Chile, } \\
\text { Colombia, Costa Rica, Estados } \\
\text { Unidos, México, Hong Kong, } \\
\text { Japón, } \\
\text { Corea, Nueva Zelanda, Noruega, } \\
\text { Paraguay, } \\
\text { Singapur, Suiza y la Unión } \\
\text { Europea. }\end{array}$ & $\begin{array}{l}\text { Grupo que busca faci- } \\
\text { litar el comercio con la } \\
\text { revisión de las reglas sobre } \\
\text { simplificación de trámi- } \\
\text { tes en aduanas, tránsito } \\
\text { y transparencia reglas } \\
\text { multilaterales sobre Faci- } \\
\text { litación del Comercio y la } \\
\text { pronta implementación del } \\
\text { Acuerdo. }\end{array}$ \\
\hline $\begin{array}{l}\text { Grupo Friends } \\
\text { of Antidumping } \\
\text { Negotiations } \\
\text { (FANS) }\end{array}$ & $\begin{array}{l}\text { Brasil, Colombia, Corea, Costa } \\
\text { Rica, Chile, Hong Kong, Israel, } \\
\text { Japón (coordinador), México, } \\
\text { Noruega, Singapur, Suiza, Tai- } \\
\text { landia, Taipéi Chino y Turquía. }\end{array}$ & $\begin{array}{l}\text { El grupo busca fortalecer } \\
\text { las disciplinas del Acuerdo } \\
\text { Antidumping para de } \\
\text { evitar el uso de medidas } \\
\text { antidumping con fines } \\
\text { proteccionistas. }\end{array}$ \\
\hline $\begin{array}{l}\text { Grupo Amigos } \\
\text { del Pez }\end{array}$ & $\begin{array}{l}\text { Argentina, Australia, Chile, } \\
\text { Colombia, Costa Rica, Ecuador, } \\
\text { Islandia, Nueva Zelandia, No- } \\
\text { ruega, Pakistán, Perú, Filipinas, } \\
\text { Estados Unidos }\end{array}$ & $\begin{array}{l}\text { Impulsa disciplinas efec- } \\
\text { tivas contra los subsidios } \\
\text { que producen sobre-explo- } \\
\text { tación de la pesca. }\end{array}$ \\
\hline
\end{tabular}

Nota: Ronald Saborío (2014).

En la actualidad Costa Rica participa de las siguientes negociaciones en curso (tabla 4): 
Tabla 4.

Participación de Costa Rica en negociaciones en curso

\begin{tabular}{|c|c|c|}
\hline Nombre & Integrantes & Objetivos \\
\hline $\begin{array}{l}\text { Acuerdo sobre el } \\
\text { Acuerdo de Servi- } \\
\text { cios (TiSA) }\end{array}$ & $\begin{array}{l}\text { Australia, Estados Unidos } \\
\text { (coordinadores), Canadá, Chile, } \\
\text { Colombia, Corea, Costa Rica, } \\
\text { Hong Kong, Islandia, Israel, } \\
\text { Japón, Liechtenstein, México, } \\
\text { Nueva Zelandia, Noruega, } \\
\text { Pakistán, Panamá, Paraguay, } \\
\text { Perú, Suiza, Taiwán, Turquía y } \\
\text { la Unión Europea. }\end{array}$ & $\begin{array}{l}\text { Negociación de un acuer- } \\
\text { do plurilateral sobre el } \\
\text { comercio de servicios } \\
\text { amplio y que consolide al } \\
\text { menos el nivel de liberali- } \\
\text { zación actual. El objetivo a } \\
\text { largo plazo es incorporar los } \\
\text { resultados de estas negocia- } \\
\text { ciones en la OMC. }\end{array}$ \\
\hline $\begin{array}{l}\text { Negociación pluri- } \\
\text { lateral sobre bienes } \\
\text { ambientales }\end{array}$ & $\begin{array}{l}\text { Australia, Canadá, China, } \\
\text { Costa Rica, la Unión Europea, } \\
\text { Hong Kong (China), Japón, Co- } \\
\text { rea, Nueva Zelanda, Noruega, } \\
\text { Singapur, Suiza, Taipéi Chino y } \\
\text { Estados Unidos. }\end{array}$ & $\begin{array}{l}\text { Liberalización del comercio } \\
\text { de bienes ambientales. }\end{array}$ \\
\hline $\begin{array}{l}\text { Grupo de expansión } \\
\text { del Acuerdo sobre } \\
\text { Tecnologías de In- } \\
\text { formación ("ITA") }\end{array}$ & $\begin{array}{l}\text { Albania, Australia, Canadá, } \\
\text { Colombia, Corea, Costa Rica, } \\
\text { China, El Salvador, Estados } \\
\text { Unidos, Filipinas, Guatemala, } \\
\text { Hong Kong, Islandia, Israel, } \\
\text { Japón, Malasia, Mauricio, } \\
\text { Montenegro, Nueva Zelandia, } \\
\text { Noruega, República Dominica- } \\
\text { na, Singapur, Suiza, Tailandia, } \\
\text { Taipéi Chino, Turquía y la } \\
\text { Unión Europea. }\end{array}$ & $\begin{array}{l}\text { Ampliar y modernizar la } \\
\text { cobertura de productos del } \\
\text { Acuerdo sobre Tecnología } \\
\text { de la Información (en vigor } \\
\text { desde 1997). }\end{array}$ \\
\hline
\end{tabular}

\section{Nota: Ronald Saborío (2014).}

En materia de cooperación comercial propiamente dicha, tal y como se desprende de la Política de Cooperación Internacional de Costa Rica, las iniciativas impulsadas se han priorizado y enfocado en las siguientes categorías: 
a. "Infraestructura relacionada con el comercio (carreteras, puertos y telecomunicaciones

b. Capacidad productiva, incluyendo la inversión orientada a diversificar las exportaciones y aprovechar las ventajas comparativas

c. Asistencia técnica para elaborar estrategias comerciales y para negociar acuerdos y aplicar los resultados alcanzados con mayor eficacia (donde ha tenido mayor participación como cooperante la OMC)

d. Asistencia para el reajuste". (MIDEPLAN, 2014, p. 119)

Señala MIDEPLAN (2014) en el documento sobre Política de Cooperación Internacional de Costa Rica que las iniciativas que han tomado la forma principalmente de capacitación, asistencia técnica o cooperación técnica, se han traducido en apoyo que le han permitido al país lo siguiente:

a. Fortalecer las destrezas del recurso humano para participar en los procesos de negociación comercial, a través de los cuales se ha construido una plataforma comercial, así como la de los equipos técnicos responsables de asegurar la aplicación efectiva de los compromisos asumidos.

b. Adquirir o actualizar equipos de hardware y software para el manejo apropiado de la información relacionada

c. Financiar algunos de los costos relacionados con la organización y participación en negociaciones (como instalaciones apropiadas para celebrar reuniones como anfitrión y gastos de transporte internacional para asistir a las reuniones en otros países)

d. Contratar consultores externos que brinden asesoría especializada en temas específicos

e. Publicar materiales informativos sobre los procesos de apertura comercial en que el país participa

f. Establecer una organización institucionalizada para vincular a las pequeñas y medianas empresas al esfuerzo exportador, mediante el encadenamiento como suplidoras de bienes y servicios para empresas extranjeras con inversiones en el país. 
g. Fortalecer el proceso de reforma del mercado de telecomunicaciones, ajustado a las nuevas condiciones de la apertura

h. Promover algunas inversiones públicas para mejorar la infraestructura relacionada con el comercio internacional

i. Ampliar, consolidar y racionalizar la plataforma de comercio exterior

j. Fortalecimiento de instituciones establecidas para administrar el comercio

k. Mejorar el clima de inversión y la creación de capacidad para maximizar el aprovechamiento de la plataforma comercial, incluyendo procesos de modernización y actualización de los sistemas internos que afectan la competitividad. (MIDEPLAN, 2014, pp. 119-120)

Sin embargo, los avances del gobierno Solís Rivera han sido muy escasos y el país demanda tomar medidas urgentes en los aspectos anteriormente indicados.

Finalmente, es importante mencionar que en un mundo internacionalizado y de alto relacionamiento comercial, para las pequeñas economías como Costa Rica y con menor peso relativo en la comunidad internacional, ser miembro de la $\mathrm{OMC}$ representa ventajas significativas que se traducen, según Adriana Campos Azofeifa, Directora del Centro de Referencia de la OMC en Costa Rica (2014) en "sistema de respaldo de obligaciones y deberes en comercio internacional".

El sistema del OSD (Órgano de Solución de Diferencias) es neutro y ha demostrado no siempre estar a favor de los países con mayor peso político y económico, representa menores costos de transacción: atender múltiples temas del comercio internacional con varios países en un solo foro internacional, acceso a trato especial y diferenciado: Los países en desarrollo y menos adelantados cuentan con mayores flexibilidades para el cumplimiento de sus obligaciones y con apoyo técnico o financiero para desarrollar capacidades para el comercio internacional o para la implementación de políticas globales del comercio. 


\section{Consideraciones finales}

Tal acción llevó al gobierno a brindar un gran apoyo a la inversión extranjera directa, a los sectores que estaban ligados al comercio exterior, diversificando la producción, buscando nuevos mercados para los productores nacionales y modificando la política cambiaria a través de pequeñas devaluaciones para incentivar las exportaciones.

Los cambios con esta política comercial se comenzaron a ver a través de la apertura a nuevos mercados, competitividad, mayores oportunidades de empleo, aumento de los flujos de intercambio y en la producción nacional, redundando todo en bienestar social y económico.

De acuerdo con el Plan Nacional de Desarrollo María Teresa Obregón Zamora (2010-2014), las prioridades nacionales en materia de competitividad e innovación se orientaron a fortalecer los siguientes aspectos:

a. El fortalecimiento del capital humano y la innovación

b. La construcción de infraestructura física

c. La inserción con éxito en los mercados internacionales

d. La eliminación y la simplificación de trámites.

Un objetivo primordial de la política de comercio exterior del país es " $a l$ canzar mejores niveles de vida para todos los costarricenses mediante el desarrollo económico y social del país" (OMC, 2001, p. 29), y para lograrlo debe implementar una productividad más eficiente para elevar los niveles de crecimiento de las exportaciones por medio de cambios en la política económica interna.

Por lo anterior, la política exterior de Costa Rica está cimentada sobre tres ejes:

a. La consolidación, ampliación y racionalización de la plataforma de comercio exterior

b. La optimización de su funcionamiento

c. La potenciación de su máximo aprovechamiento. (Plan Nacional de Desarrollo de Costa Rica, 2010-2014) 
El Ministerio de Comercio Exterior (COMEX) ha sido el ente encargado de regir la actividad comercial del país, desde un marco institucional y jurídico permanente que ha brindado el asesoramiento adecuado para insertarlo en el mercado internacional, junto con la liberación del comercio que se llevó a cabo en el mundo desde 1992.

Cuenta con dos instituciones: Una se encarga de promover la oferta exportable en el exterior, en especial las pequeñas y medianas empresas, llamada Promotora de Comercio Exterior (PROCOMER); la otra es una organización privada cuyo objetivo es ofrecer, a través de programas de inversión, las condiciones más atractivas para inversionistas nacionales y extranjeros, llamada Coalición Costarricense de Iniciativas de Desarrollo (CINDE).

Adicionalmente, el país ha tenido una activa participación en el Sistema Multilateral de Comercio, por más de dos décadas desde que se adhirió en 1990 al GATT, estuvo presente en las negociaciones de la Ronda de Uruguay que dieron origen a la OMC en 1995 y desde ese momento fue miembro fundador de esta organización.

Desde su adhesión al Acuerdo General sobre Aranceles Aduaneros y Comercio (GATT) en 1990 y su posterior ingreso como miembro fundador, en 1995 de la Organización Mundial de Comercio (OMC), Costa Rica ha dispuesto de un amplio conjunto de normas y reglas claras para su participación como competidor, como oferente y como demandante de bienes y servicios en el escenario internacional.

Dicha participación conjuntamente con la atracción de la inversión extranjera, la promoción de las exportaciones, la política de comercio exterior, la integración centroamericana, los tratados de libre comercio y la participación en el sistema multilateral de comercio son los instrumentos sobre los cuales el país ha puesto su mirada para desarrollar la política comercial.

En el marco de la participación del país en el foro multilateral del comercio, Costa Rica ha echado mano a los instrumentos que la organización ofrece para lograr mejores condiciones de acceso para sus productos y para defender sus intereses comerciales, a través de los mecanismos de solución de diferencias.

La participación de Costa Rica en el marco del sistema multilateral de comercio a lo largo del periodo 2001-2014 le ha permitido al país contar con una amplia plataforma para promover, fortalecer e incrementar el comercio internacional, garantizar a la nación que sus exportaciones de bienes y servicios están sujetas a reglas claras y justas en los mercados de destino y fortalecer su política comercial en todos sus ámbitos. 
ENERO - JUNIO - 2016 JEANNETTE VALVERDE C. · DEYDA M. MONGE U.

REVISTA 89.1

Sin duda, el sistema multilateral ha generado en sus países miembros un marco jurídico amplio que le otorga condiciones de estabilidad y seguridad para la liberalización comercial, como herramienta para el crecimiento económico y ha abierto oportunidades para la participación de nuevos actores en el escenario internacional.

De gran beneficio para el país será continuar con la promoción de las pequeñas y medianas empresas mediante su oferta exportable en mercados internacionales e involucrar la actividad exportadora a todos los sectores del país.

Otro aspecto que deben tener presente las autoridades es defender, del proteccionismo comercial de otros países, a los sectores exportadores nacionales y ofrecer mayores facilidades tanto para la inversión nacional como extranjera: Atractivos y ventajosos programas en donde los sectores se sientan optimistas a participar con reglas y procedimientos para un adecuado uso de las relaciones comerciales. 


\section{Referencias}

Centro de Comercio Internacional/ UNTAD/OMC/. (1995). Guía de la Ronda Uruguay para la Comunidad Empresarial: Ginebra. Autor.

Chinchilla Miranda, Laura. (Marzo, 04, 2016). Lamy inaugura el Foro Público de la OMC, la Presidenta de Costa Rica pide "flexibilidad" para la Ronda de Doha. Recuperado de: https://www.wto.org/spanish/news_s/news11_s/ chinchillla_s.htm

Campos Azofeifa, Adriana. Directora, Centro de Referencia de la OMC en Costa Rica. IICA. Entrevista sostenida el 26 de abril de 2014.

ICAP- PNUD. (s. f.). Publicación conjunta en el marco del Proyecto CAM-92-003: San José.

Ley 7638. (1996). Creación de COMEX y PROCOMER, Costa Rica.

MIDEPLAN (2014) Política de cooperación Internacional de Costa Rica. San José, Costa Rica

MIDEPLAN. (2010). Plan Nacional de Desarrollo de Costa Rica, 2010-2014. Costa Rica.

Ministerio de Comercio Exterior. (2001). Costa Rica y la Organización Mundial del Comercio, Costa Rica.

Ministerio de Comercio Exterior. (s. f.). Adhesión de Costa Rica al GATT, Costa Rica.

Ministerio de Comercio Exterior. (1997). Comportamiento y Perfil de la Inversión Extranjera Directa en Costa Rica. San José.

Nonalaya, Lisseth. (2014). Seminario Introductorio al Sistema Multilateral de Comercio, Costa Rica.

Organización del Comercio. (1996). El Comercio y la Inversión Extranjera Directa: Ginebra.

Organización Mundial del Comercio. (1995). Examen de las políticas comerciales. Costa Rica.

Organización Mundial del Comercio. (2007). Examen de las políticas comerciales. Costa Rica.

Organización Mundial del Comercio. (2013). Examen de las políticas Comerciales. Costa Rica. Recuperado de: (http://www.wto.org/spanish/tratop_s/tpr_s/ s286_s.pdf). (Marzo 04, 2016) 
Organización Mundial del Comercio. (2010). Entender la OMC. Ginebra, Suiza.

Organización Mundial del Comercio. (s. f.). Diez cosas que puede hacer la OMC. Ginebra, Suiza.

Organización Mundial del Comercio. (2009). Los textos de la Ronda de Doha y documentos conexos. Ginebra, Suiza.

Organización Mundial del Comercio. (2009). El futuro de la OMC: Una respuesta a los desafíos institucionales del nuevo milenio. Ginebra, Suiza.

Organización Mundial del Comercio. (2014). Creación de capacidad comercial. Informe anual 2014. Recuperado de http://www.wto.org/spanish/res_s/ booksp_s/anrep_s/anrep14_chap8_s.pdf (enero 13, 2015.

Organización Mundial del Comercio. (2014). Comité de Comercio y Desarrollo. Plan bienal de Asistencia técnica y formación 2014-2015. Recuperado de: file://C:/Users/RI/Documents/Downloads/W200.pdf. (enero 13, 2015)

PNUD-AECID. (2010). Manual de cooperación técnica entre países en desarrollo y triangulación: San José, Costa Rica.

Rodríguez Oconitrillo, Pablo. (1992) Notas sobre el Estado costarricense y los retos del GATT. Escuela de Relaciones Internacionales, Universidad Nacional, Costa Rica.

Saborío, Ronald. (2014) Seminario Introductorio al Sistema Multilateral de Comercio, Costa Rica.

Saborío, Ronald. (2014. Cronología de la Política exterior. Recuperado de: http:// www.slideshare.net/marconabu/costa-rica-en-la-organizacin-mundial-delcomercio. (enero 5, 2014)

OMC. Ronda de Doha. (2014). PLAN BIENAL DE ASISTENCIA TÉCNICA Y FORMACIÓN 2014-2015. Recuperado de: file://C:/Users/RI/Documents/ Downloads/W200.pdf) ( agosto 14, 2014)

OMC. (Agosto, 13, 2014). Creación de capacidades. Recuperado de: http://www. wto.org/spanish/tratop_s/devel_s/build_tr_capa_s.htm el

OMC. (Agosto, 13, 2014). Comité de Gestión. Recuperado de: http://www.wto. org/spanish/tratop_s/devel_s/teccop_s/tamc_s.htm

OMC. (Agosto, 17, 2014). Sistemas multinacionales GATT-OMC. Recuperado de: http://www.wto.org/spanish/tratop_s/dda_s/dda_s.htm 